\title{
Old Crystallizing Galactocele - A Rare Case Report
}

Samoon Nuzhat ${ }^{1 *}$, Shah Qayoom ${ }^{2}$, Qureshi Zubair ${ }^{1}$ and Bashir Nusrat ${ }^{3}$

${ }^{1}$ Department of Pathology and Transfusion Medicine District Hospital Baramula, Jammu and Kashmir, India

${ }^{2}$ Department of Surgery District Hospital Baramulla, Jammu and Kashmir, India

${ }^{3}$ SKIMS Soura, Jammu and Kashmir, India

*Corresponding author: Nuzhat Samoon, Department of Pathology and Transfusion Medicine, District Hospital Baramula, Jammu and Kashmir, India, Tel: 9906638617; E-mail: samoon.nuzhat@gmail.com

Rec date: Dec 02, 2014, Acc date: Apr 28, 2015, Pub date: Apr 29, 2015

Copyright: (C) 2015 Nuzhat S, et al. This is an open-access article distributed under the terms of the Creative Commons Attribution License, which permits unrestricted use, distribution, and reproduction in any medium, provided the original author and source are credited.

\begin{abstract}
Galactoceles are benign cystic lesions generally occurring during pregnancy and lactation. Fine needle aspiration yields milky fluid that is often both diagnostic and therapeutic. Galactoceles are non-infective due to sterile environment and have no access to the outer environment. Crystallisation of the milky fluid takes place very rarely.
\end{abstract}

Keywords: Breast; Old crystallizing galactocele; Aspiration cytology

\section{Case}

A 35 year old female presented with a $3 \times 3 \mathrm{~cm}$ discrete, non-tender nodule involving the lower outer quadrant of left breast since 3 years. FNAC showed bifrengent angulated crystals of varying size and shape and amorphous material in MGG (MayGrunWald - Geimsa) (Figures 1A-C). She had delivered a baby boy three years back and had presented with a swelling breast same site after a period of 6 months. FNA done had revealed features of a galactocele with aspiration of 5 $\mathrm{ml}$ of milky fluid with decreased size of the swelling. Now she has presented after 3 years since then with a clinical impression of a fibroadenoma breast. We performed 2 needle passes which resulted in the aspiration of thick chalky white material that obstructed the needle. In view of clinical history and cytology, a diagnosis of a crystallization of a galactocele was made.
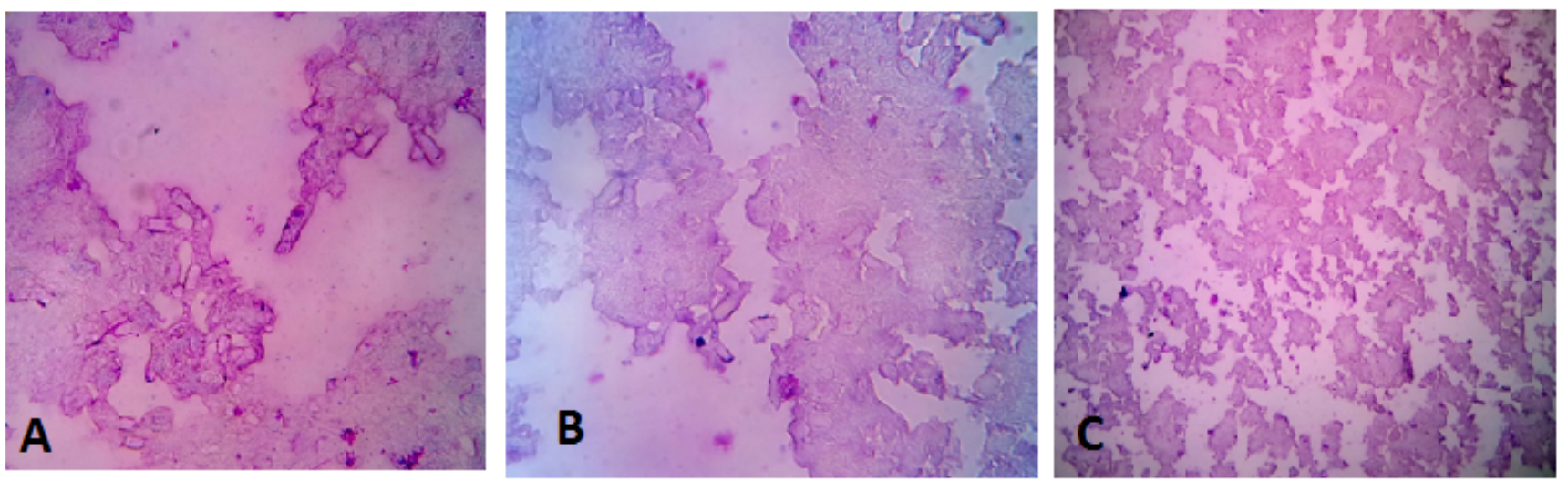

Figure 1: FNAC showed bifrengent angulated crystals of varying size and shape and amorphous material in MGG (MayGrunWald - Geimsa).

The cytological features of a galactocele which are considered to be specific to pregnancy and lactation were assessed by two small series [1] and by three case reports of Raso et al. [2], Nikumbh et al. [3], and Jyothi et al. [4].

\section{Discussion}

A galactocele is an uncommon benign lesion of breast resulting from the obstruction of the duct. In addition to lactation ,several breast lesions which result in a ductal obstruction [2] or a generalized condition such as a breast surgery, the transplacental passage of prolactin, and oral contraceptives can create the factors for the development of a galactocele $[1,2]$.

Unusual feature of a galactocele- crystallizing galactocele makes us to report this case. To the best of our knowledge our case is the fourth case report after Raso et al. [2] and Nikumbh et al. [3], Jyoti et al. [4].

\section{References}

1. Kline TS (1981) Masquerades of malignancy; A review of 4241 aspirates from breast. Acta Cytol 25: 263-266. 
Citation: Nuzhat S, Qayoom S, Zubair Q, Nusrat B (2015) Old Crystallizing Galactocele - A Rare Case Report. J Cytol Histol 6: 325. doi: 10.4172/2157-7099.1000325

Page 2 of 2

2. $\quad$ Raso DS, Greene WB, Silverman JF (1997) Crystallizing galactocele: A case report. Acta Cytol 41: 863-70.

4. Jyoti K, Baliga V (2015) Crytallising galactocele -a cytological delimma. Sch J App Med Sci 3: 129-130.

3. Nikumbh DB, Desai SR, Shrigondekar PA, Brahmalkar A, Mane AM

(2013) Crystallizing galactocele- An unusual diagnosis on fine needle aspiration cytology. J Clin Diagn Res 7: 604-605. 